\title{
Beyond informed choice: Prenatal risk assessment, decision-making and trust
}

\author{
Nete Schwennesen, Mette Nordahl Svendsen \& Lene Koch
}

In 2004 prenatal risk assessment (PRA) was implemented as a routine offer to all pregnant women in Denmark. It was argued that primarily the new programme would give all pregnant women an informed choice about whether to undergo prenatal testing. On the basis of ethnographic fieldwork in an ultrasound clinic in Denmark and interviews with pregnant women and their partners, we call into question the assumption underlying the new guidelines that more choice and more objective information is a source of empowerment and control. We focus on one couple's experience of PRA. This case makes it evident how supposed choices in the context of PRA may not be experienced as such. Rather, they are experienced as complicated processes of meaningmaking in the relational space between the clinical setting, professional authority and the social life of the couples. PRA users are reluctant to make choices and abandon health professionals as authoritative experts in the face of complex risk knowledge. When assumptions about autonomy and self-determination are inscribed into the social practice of $P R A$, authority is transferred to the couple undergoing $P R A$ and a new configuration of responsibility evolves between the couple and their relationship to the foetus. It is argued that although the new programme of prenatal testing in Denmark presents itself in opposition to quasi-eugenic and paternalistic forms of governing couples' decisions it represents another form of government that works through the notion of choice. An ethics of a shared responsibility of PRA and its outcome would be more in agreement with how decisions are actually made.

Keywords: informed choice, institutional framing of choice, prenatal risk assessment, prevention, processes of decision-making, trust 


\section{Introduction: the Danish case}

This paper reports from an ethnographic study of recent technology for prenatal risk assessment (PRA). Since 2004, PRA has been implemented in the Danish health care sector and routinely offered to all pregnant women, regardless of their age. The risk assessment is carried out in the first trimester of pregnancy (between weeks 11 and 13) and is a non-invasive intervention. It measures the risk of a foetus having Down's syndrome (or other chromosomal diseases) by combining maternal serum markers (HCG and PAPP-A) with an ultrasound scan (the nuchal translucency scan). Through combining these two parameters with a pregnant woman's age-related risk an overall risk figure is calculated. The risk figure provides the basis for action, i.e. the decision about whether to undergo an invasive diagnostic test, such as CVS or amniocentesis, which involves the risk of inducing a miscarriage (1\%).

Denmark was the first Scandinavian country to implement the technology as a routine offer to all pregnant women. In Norway PRA is offered to pregnant women above 38 years and women who are known to be at increased risk of having a diseased child (Bioteknologinemnda 2005). ${ }^{1}$ In Sweden PRA is offered to women above 35 years but this offer is only available in some locations (Socialdepartementet 2006). Here, a system similar to the Danish one is underway. The Swedish Medical-Ethical Board has recommended that all pregnant women be offered information about risk assessment and its implications (SMER 2007). In Iceland every pregnant woman is informed about the possibility of undergoing PRA, but if she opts to undergo assessment she has to pay for the examination herself (Kristjánsdóttir 2008). In all of these countries there is an ongoing debate as to whether or not to introduce PRA as a routine offer to all pregnant women. PRA has a high uptake in Denmark. One study in two counties in Denmark shows that only $2 \%$ of couples offered PRA in the period 1 July - 31 December 2005 actively refused the offer and it is estimated that the overall current uptake is at least $90 \%$ (Tørring et al. 2008). ${ }^{2}$ In the Copenhagen area the uptake is estimated to be app. 95\% (Tabor 2006).

The introduction of PRA as an offer to all pregnant women in Denmark is based on the development and implementation of new guidelines on prenatal testing in Denmark (Sundhedsstyrelsen [Danish Board of Health] 2003a; 2003b; 2004). The implementation of the guidelines illustrates two trends within the organisation of reproductive health in a number of Western countries. First, the guidelines express an increasing implementation of prenatal risk knowledge in the context of pregnancy (Franklin \& Roberts 2006; Helén 2005; Kerr 2004; Lock 1998; Lupton 1999; Rapp 2000; Weir 1996). In recent decades prenatal risk knowledge has been made increasingly available to pregnant women and their partners during (or even before) pregnancy. Through such practice, the biomedical category of the 
foetus at risk is created. It provides the pregnant woman and her partner with knowledge about the possibility that the pregnancy will develop into a child with Down's syndrome. In this space for action abstract risk knowledge is translated into the context of a particular life through which future foetal life is governed, such as the decision to have an abortion or undergo invasive tests which involve a risk of inducing miscarriage. Second, the guidelines express an increased emphasis on liberal values (individual autonomy and rational decision-making obtained through non-directive counselling) and a turn towards a more market-oriented method of health care delivery within programmes of prenatal testing (Helén 2005; Kerr 2004; Lemke 2005; Weir 1996). Embodying these trends, the Danish guidelines rely on (implicit) assumptions about human agency and motivation: the pregnant woman is seen as an autonomous individual who acts rationally on the basis of objective and neutral knowledge. For pregnant women and their partners, this techno-ethical development shapes new spaces of possibility that we suggest should be viewed as contemporary bio-political spaces (Rose 2001; 2007) in which etho-political questions on 'life itself' (Rose 2001) emerge and are negotiated.

Questions have been raised in the Danish debate about whether or not the policy of autonomous decision-making in connection with prenatal risk assessment works as intended. Are the users of prenatal risk assessment well informed? Are they provided with non-directive counselling? What measures may be taken to ensure that these preconditions lead to a truly informed and autonomous choice? In a European context autonomous decisionmaking has been seen as a key aspect of ethical health care in the context of prenatal testing (Dahl et al. 2006a; 2006b; Harper 2004; Hunt et al. 2006; Marteau \& Dormandy 2001; Marteau et al. 2001), and tools to measure the level of informed choice have been developed (Marteau et al. 2001; Van den Berg et al. 2006). Overall, the idea of ethical health care in the context of prenatal testing has been framed in a language of choice and as a question about having the appropriate information in order to make an informed and thus qualified choice.

In the following, we do not aim to evaluate whether or not the policy of autonomous decision-making works. Rather, we ask how it works. With this question we are interested in how PRA is practised after the implementation of the new guidelines and what implications it has for pregnant women and their partners. In doing so, we view policy as forming social practise rather than as a neutral instrument to reach a certain goal (Jöhncke et al. 2004; Shore \& Wright 1997; Svendsen \& Koch 2006). Health policies carry an intentionality about how to act correctly and as such are normative devices through which a framework of action is shaped. In this sense, they are social phenomena that contribute to the way relationships are shaped and how individuals understand themselves (Jöhncke et al. 2004). With this per- 
spective we do not wish to assess the extent to which goals such as autonomy and non-directiveness are realised. Rather, we ask what happens when assumptions about autonomy and non-directiveness are inscribed into the social practice of prenatal risk assessment: 1) Which organisational routines emerge through these social practices? 2) How are the relationship and expectations between the health professionals and the user configured and reconfigured through practice? 3) Which new identities and problem spaces emerge for couples who choose to undergo PRA?

In an attempt to answer these questions we present and analyse empirical material from an ongoing qualitative and ethnographic study of the social implications of the implementation of the guidelines at a Danish ultrasound clinic. In doing so, we draw on the growing field of empirical social science of ethics (Corrigan 2003; Hoeyer 2005; Hoffmaster 2001; Holm \& Monique 2004; Howell 1997; Konrad 2005; Lock 1998; Schwennesen 2005; see Haimes 2002 and Hedgecoe 2004 for a review). This type of approach does not seek to provide normative answers to ethical questions asked by institutionalised ethics. It is critical of the tendency of this form of ethics to ignore the social, institutional and cultural context in which decisions are made. Instead of focusing on individual rights it focuses on how notions of 'the right' and 'the good' are created in personal and social relationships; instead of focusing on assumptions of rationality and universal applicability of ethical norms it focuses on concrete lived experiences. On the basis of empirical - often ethnographic studies - it aims to explore the actual dilemmas that emerge in the context of decision-making and the process of working through such dilemmas. From this outset, our hope is that this study will serve as a contribution to what Hedgecoe (2004) calls a bottom-up 'critical bioethics' which is rooted in empirical research and which allows the problems, dilemmas and controversies analysed to emerge from particular settings where actual decisions are made rather than from pregiven philosophical theories.

\section{New guidelines on prenatal risk assessment in Denmark}

The implementation of prenatal risk assessment as a routine offer to all pregnant women in Denmark was primarily argued with the wish to give all pregnant women a choice as to whether to undergo prenatal testing (Sundhedsstyrelsen 2003a; 2003b; 2004). The old regime of prenatal examination in Denmark was based on specific access criteria, such as age; only women above 35 years or women known to be at risk of giving birth to a child with a chromosomal disorder were offered prenatal diagnosis. In a report developed by a technical expert group it was argued that the implementation of prenatal risk assessment to all pregnant women should be seen 
as part of a paradigm shift in prenatal examinations in Denmark (Sundhedsstyrelsen 2003a). The working group saw established access criteria, such as age, as being in conflict with the wish to respect pregnant women's self-determination and the group emphasised that the old guidelines represented a prevention-oriented paradigm of prenatal examination. In their view, the new guidelines, based on the norm of individual informed choice, represented a shift towards a more self-determination oriented paradigm. Following this, it was emphasised that prenatal examinations in the future should not be carried out in the interest of prevention, and therefore should not be organised as a screening programme, where the health service system 'initiate[s] examinations by suggesting, recommending or inviting users on their own initiative' (Sundhedsstyrelsen 2004: 7). In the wake of the debate about whether or not to implement PRA as an offer to all pregnant women, the Danish Government released the following statement: 'The Parliament think there is a need to emphasise that the purpose of prenatal testing is not to prevent children with serious diseases from being born, but to assist pregnant women in making their own choices' (Folketingsvedtagelse [Parliamentary Decision] 2003). This statement echoes an earlier statement from the first official report on prenatal examinations from 1977, claiming that the purpose of prenatal examinations was to 'prevent unhealthy children from being born', reduce the cost of institutionalising handicapped children, and thus establish a cost-effective system of prenatal examinations (Indenrigsministeriet [Ministry of the Interior] $1977,8)$. The latter statement has often been regarded as proof that the previous guidelines had a eugenic objective, and their explicit rejection plays a central role in the attempt to publicly present the new guidelines as free of any links to a problematic past.

By referring to this statement, the maintenance of age as the main access criteria was described as difficult to legitimate (Sundhedsstyrelsen 2004). Other arguments for introducing PRA as a routine offer to all pregnant women mentioned in the guidelines include a wish to decrease the amount of invasive interventions (CVS or amniocentesis) and the unintended induced miscarriages following such examinations.

\section{The cut-off point}

In spite of The Danish Board of Health's aim to orient the programme of prenatal testing in Denmark towards self-determination and patient autonomy, the Danish Board of Health has established a new limit of access to the programme. The result of PRA is an overall risk figure, which is expressed as a relational figure on an infinite scale (e.g.1:200, 1:800 or 1:10,000). The Danish Board of Health suggests that the obtained risk figure should be 
the basis for women's access to invasive testing. In doing so, they suggest creating a cut-off point at 1:250, which implies that only women who have a risk higher than or equal to 1:250 will automatically be offered invasive examinations (in practice, the cut-off point remains contested among Danish hospitals and ranges between 1:250 and 1:400). The cut-off point obviously illustrates the need to establish access criteria to prenatal testing within a tax financed programme of prenatal testing but simultaneously reflects an implicit political decision as to the right balance between the aim of self-determination and the aim of prevention in the new programme of prenatal testing in Denmark.

The cut-off point is calculated on the basis of a large sample of epidemiological data (Nicolaides 2004) and expresses a relationship between detection rate, false positive rate and economic costs. If the cut-off point is high only a few women will be given access to invasive tests, the detection rate will be low, the false positive rate will be low, and the socio-economic costs will be high (a greater number of children with Down's syndrome will be born, and require care). Conversely, if the cut-off point is low, a high number of women will be given access to invasive tests, the detection rate will be high, the false positive rate will be high, and the socio-economic costs will be low. Thus, there is a trade-off between these factors, and where the exact limit is set is not objectively evident, but is based on normative and political decisions balancing the different interests. In this sense the cut-off point expresses normative and political intentions and values about the desired outcome of the programme on a population level, values that have not been explicitly admitted by political decision makers. No official discussion on the right balance between the different interests were initiated in Denmark, and thus the implicit cost-benefit considerations are not made visible in the present guidelines as they have been in previous ones (Indenrigsministeriet 1977).

Conspicuously, no considerations of the relationship between the cutoff point and the risk of inducing a miscarriage by undergoing an invasive examination (app. 1\%) are made in the guidelines. By setting the cut-off point lower than the risk of inducing a miscarriage by undergoing invasive examinations a situation might be created where the risk of undergoing the examination is higher than the possibility that the foetus has Down's syndrome, i.e. if a pregnant woman as assessed as having a risk figure of 1:200, she will be offered an invasive examination. If she accepts the risk of inducing miscarriage of a healthy baby by having the examination would be higher than the possibility of detecting a foetus with Down's syndrome. A pregnant woman faced with this dilemma has to choose between not having an invasive examination and thus run the risk of having a child with Down's syndrome or having an invasive examination and thus running (a higher) risk of inducing miscarriage of a healthy child. From an individual perspec- 
tive it may look as if the Danish Board of Health implicitly evaluates the prospect of a child being born with Down's syndrome as more dangerous than the prospect of a healthy child being aborted through an invasive examination by installing a cut-off point which is lower than the risk of inducing a miscarriage by undergoing the test. This illustrates a conflict between achievements on a population level versus achievements on an individual level and indicates that the programme of prenatal testing in Denmark is built upon and shaped by preventive values (Koch 2003).

The first retrospective epidemiological study on data from Danish pregnant women undergoing PRA shows that the new programme on prenatal testing in Denmark is very successful in terms of prevention. The study was carried out in two Danish counties and covered the period between 1 July and 31 December 2005. In this period a cut-off point of 1:400 was used. The detection rate was measured to be $85 \%$ and the false positive rate was measured to $3.4 \%$. When a cut-off point at 1:250 was used, the detection rate was $85 \%$ and the false positive rate fell to $2.6 \%$. During the period an increased number of foetuses with Down's syndrome were diagnosed prenatally as compared to previous practice ${ }^{3}$ (Tørring et al. 2008). Even though the Danish Board of Health does not characterise the new programme of prenatal testing in Denmark as a preventive screening programme, this study indicates that it is more effective in obtaining the goals of prevention that the previous programme.

\section{The study}

The present paper is based on an ongoing ethnographic and interview study of the implementation of the new guidelines at an ultrasound clinic in Denmark. During a six-week period in 2005 the first author (NS) undertook participant observation at an ultrasound clinic. She followed and observed the social practices of PRA in the clinic, she participated in several ultrasound scans, and observed the health professionals' calculation of the risk figure and the communication of the risk figure to the pregnant women and their partners. Moreover, she conducted interviews with 14 couples who underwent PRA in the study period. The couples were chosen on the basis of a criterion of diversity in terms of age and risk.

In the following, we focus on one case which illustrates one pregnant woman and her partner's journey through PRA. The story is about Peter and Patricia, who were assessed as having a risk figure of 1:661 ${ }^{4}$. This specific case was selected because it makes evident the problems of communicating complex risk information in a non-directive way (Peter and Patricia had a risk figure which is below the cut-off point, but above Patricia's agerelated risk) and it highlights the difficulties couples face when they try to 
use complex risk information as a basis for decision-making. As will be seen, the case challenges the dominant view that neutral information serves the purpose of patient empowerment and control, and that decisions are reached as autonomous and rational discrete acts of choice. Rather, their case highlights how the implicit preventive norms of PRA play a crucial role in shaping the decisions being made. ${ }^{5}$

\section{Entering PRA}

Patricia and Peter became aware of the possibility of undergoing PRA from their local GP, who is responsible for providing the first information about PRA in the Danish health care system. At the meeting several health care services were presented to them, such as undergoing pregnancy check-ups by the midwife and the GP. Patricia and Peter told NS that they had never really questioned whether or not to undergo PRA, and they described the decision as a routine act. Patricia said, it was just sort of «yes please», we accept that, just as we accept midwife and antenatal care. We accept the whole package. They were very happy to have the possibility of undergoing PRA and did not question its effectiveness in detecting unhealthy foetuses, nor did they have any doubts about whether or not to participate. Overall, they saw PRA as 'an offer that you can't refuse. This notion of PRA as an offer one cannot refuse was shared by all interviewees and is also described as characteristic of the users' entrance into PRA in another Danish study (Lou et al. 2007).

According to the guidelines, undergoing PRA is a choice made by the couple concerned. Yet, Peter and Patricia's description of their entrance into PRA points to the way in which a shared understanding about PRA (and expert knowledge in general) was created in the relational practice of being informed about PRA by their GP. Sharing the value of PRA meant that they hardly experienced making a choice. Rather, PRA appeared as 'a «default» pathway' (Webster 2007: 470). It became an obligatory passage point on a normal trajectory towards having a healthy baby. So, what in the guidelines is described as an autonomous and informed choice was, in the conversation with the GP, performed as a routinised and non-problematised act. The decision to undergo PRA had the character of what Webster (2007: 470) refers to as 'informed compliance. With this statement we do not imply that the particular GP did not do her job properly, but rather we wish to render visible the importance of the normativity of the organisational context in which choices are made. The organisation of the PRA was taken for granted and the couple's general acknowledgement and appreciation of expert knowledge meant that the PRA was practised as 'part of the package'. 
When describing to NS their motives for undergoing PRA, Patricia said, 'we have used it to prove that there is something in there.' On the other hand, they were also aware of the prospect of achieving knowledge about whether or not something was 'wrong' with the foetus. Peter said, 'if it is possible in any way to rule out that something is wrong with the foetus, then you want to do that'. This illustrates how PRA serves two different and somewhat contradictory purposes for pregnant women and their partners. First, there is confirmation that the pregnancy is real and the foetus is alive, and second, knowledge is provided about whether something is 'wrong' with the foetus and, if so, a provision of strategies for how to act in the present so as to avoid specific futures (giving birth to a child with Down's syndrome). Being aware of these two possible outcomes of PRA, Patricia and Peter were both nervous and exited before undergoing PRA: 'nervous that something might be wrong with the foetus and excited to see if there really was something in there', Patricia said. Patricia emphasised at the same time that she had not thought through how she would act if the PRA were to indicate that something was wrong with the foetus. 'I have not taken that step.'

The scan confirmed Patricia and Peter's belief that pregnancy was real and that there actually was a foetus 'in there. The nurse contributed to this sense of realness by marking out on the screen the physical parts of the foetal body and by describing the foetus as having personal characteristic such as being active. When NS talked to Patricia and Peter after the scan they explained that undergoing the scan was a very pleasant and calming experience for them. According to Patricia, 'you could see the child straight away. I was really happy, I smiled all the time, and yes, we could see that everything was OK ... the little one romped around, and we could see the fingers and the nose very clearly and the heart beat and so ... it was fantastic'. Seeing the image of the foetus on the screen thus confirmed Patricia's and Peter's hope that a healthy and living foetus (child) was inside Patricia's belly.

If we sum up how the guidelines' assumptions about autonomy and choice are inscribed into social practice, Peter and Patricia's case demonstrates that the first 'autonomous choice, i.e. the decision to undergo scan and risk assessment, is experienced by couples as part and parcel of the public antenatal health care services that they trust. In this sense, entering PRA becomes a non-decision as it is not questioned but rather experienced as a recommendation put forward by authoritative professionals. What contributes to this non-decision is the absence of talk about what to do in the case of a high risk of an abnormality. This issue is neither brought into the consultation with the GP, nor does it frame couples' experience of the PRA although they may be fully aware that the PRA implies a risk figure. This means that the PRA is primarily practised and experienced as a possibility for affirmation about one's pregnancy and as the obvious route towards a 
healthy baby, whereas the possibility of a positive finding - and an unhealthy baby - is repressed.

\section{Communicating and receiving risk figures}

In the case of Peter and Patricia, after the scan the nurse went into a separate room to calculate the risk figure, while the couple waited in the hall together with three other couples. After having waited for 10 minutes the nurse called them into a separate room to give them information about the results of the risk assessment. During this session Patricia and Peter learned that the result of their PRA was 1:661. They were told that Patricia's age-related risk was 1:907, which was lower than her final risk of 1:661 and that it was the double test which increased her risk. Transcripts from the session when the risk information was given to them are presented in the following:

Nurse: If we look at your age risk exclusively, the so-called background risk, then your risk is 1:907. This is the risk you enter the room with. If we look at the size of the nuchal translucency and the double test, then your risk figure decreases.

Patricia: Oh, that's great.

Nurse: Or, no - yes. It increases. The figure decreases and the risk goes up. Do you see? It is 1:661.

Peter: Yes.

Nurse: And this is the thing about looking at the figures. You can say that your risk at arrival is lower than your risk at departure.

Patricia: Mmm, well, OK.

Nurse: The reason is not your age, because you are young. It is the double test, which increases the risk. If you look at the figure from the nuchal translucency alone, then your risk is lower than your agerelated risk, but the double test pulls the risk the other way. We can conclude from this by saying that when the overall risk is around 1:300 or is higher than 1:300, then you are automatically eligible for a CVS or an amniocentesis. So... how do you feel about these figures?

Patricia: Well ... our figure is 1 out of 661, and it has to be 1 out of 300 before you...

Nurse: We have a cut-off, where we say ... well, you have to have a limit, because there is also a risk of inducing a miscarriage by undergoing CVS.

Patricia: It is difficult to evaluate, but I think that it looks OK, but I do not ... I do not know much about this, so ...

Nurse: A lot of people are puzzled when they are assessed as having a risk higher than the one they arrived with ... 
Patricia: But still it is extremely low.

Nurse: You may give birth to 661 children before you will have a diseased one.

Patricia: Well, I don't think there is a reason to undergo any further tests, but what do you think? Oh, I can't ask you that?

Nurse: You may ask me [laughing], but it is difficult for me to answer, because I am not you, so ...

Patricia (to Peter): Yes, OK, but do you think it seems like a high risk? Peter: I don't know anything about this. What do I know?

Nurse: No, its ...

Peter: What do other couples do?

Nurse: People have simply very different ways of reacting to this.

Peter: No, I mean, which figure do they get? Is 661 normal, or ...?

Nurse: It is different... You have your age, you have maternal age, you have the size of the nuchal translucency and you have the double test. So you have to find one who has exactly the same age and the same double test before you can say anything, right? Some have a risk at, say 1 to 6000 .

Patricia: Yes.

Nurse: And some have a risk ... or, if it is 1:3, then most people will choose to undergo further examinations, right?

Patricia: Yeah, that's clear.

Nurse: But people react very differently to the figures, and to what they consider the best thing to do. You can say 1 out of 661 , is ... it is only 1 out of $661(\ldots)$ there is a much better chance that everything is OK, right?

Patricia (to Peter): I am not disturbed by this, but what do you say? Is it something we have to think about?

Peter: Yeah, but it is statistics, I am so bad at ...

Patricia: But just try to think about if you had to draw 1 out of 661 in a lottery, what would you think you would get?

Peter: That I would not have it.

Nurse: Well, I, we would also not say ...

Peter: But what is normal? Is 1 to 800 or 1 to 2000 normal, or ...?

Nurse: It can be very different, very different, yeah.

Peter: It is just a figure. It isn't informative when you have nothing to compare to.

Patricia: No.

Nurse: What you can compare to is the age-related risk, the adjusted risk and the cut-off point, which have been established to evaluate what is good and what is less good. 
This extensive quote from the interview with Peter and Patricia illustrates a number of points. While a risk figure in an epidemiological setting is about relationships located outside any given individual, its role in a clinical setting is to assist in the diagnosis and management of a specific patient (Gifford 1986: 221). Thus, a risk figure is transformed from saying something about the population to saying something about the individual (Gifford 1986: 222). What is spelled out in the conversation between Peter, Patricia and the nurse, however, is that this 'something' that the risk figure predicts does not follow from the figure itself. The figure has to be invested with meaning to make sense and this proves to be a difficult task. Throughout the conversation between the three of them the risk figure appears as an indication of both a high risk (a possibly diseased baby) and a low risk (a probably) healthy baby. By inviting Peter and Patricia into a separate room instead of the usual procedure of providing the couple with their photo and risk figure in the hall, the nurse indicates their special situation. Inviting couples into a separate room is normal procedure when having to communicate a risk figure that is high and may result in a discussion about further examinations. Thus, the spatial relations of the whole dialogue communicated that Patricia and Peter's risk figure was considered high and that another trajectory than the usual one of being wished a happy pregnancy might be open to them: the trajectory of undergoing CVS or amniocentesis. Following this initial problematisation of the risk figure, emphasised by the organisation of space, the nurse emphasised the difference between their age-related risk (the one they entered the room with) and their actual risk. Through this comparison the risk figure appeared high. Implicitly, the notion of high risk also came to the fore when the nurse mentioned the cutoff point. She did not use the cut-off point to tell them that they were far from it and therefore should leave the clinic happily, with a very low risk. Rather, she asked them what they thought about their risk figure in comparison with the cut-off point. In this sense, her mentioning of the cut-off point may be interpreted as a further problematisation of the couple's risk figure and as an indication that although their risk figure did not automatically make them eligible for further investigations, it might have been a possibility anyway.

During fieldwork we have encountered cases in which women with a risk figure lower than 1:300 (like Peter and Patricias risk figure) have expressed a strong wish to undergo further examination and that their requests have been met with reference to the need to respect patient perspectives and autonomy on this basis. We interpret the nurse's question 'how do you feel about these figures?' as her way of apprehending whether or not Peter and Patricia had a query about further examinations, and the fact that she had located the conversation in a separate room indicates that she might have been willing to meet a possible request if it had made. Thus, 
the spatial organisation of the conversation, together with the reference points given by the nurse (age-related risk and cut-off point), express the risk figure as a problem and suggest consideration of further examinations as the solution. We were not the only ones to experience this problematisation of the risk figure; as we will discuss in the next section, this experience of a problem was also shared by Peter and Patricia.

At the same time as when the nurse more or less implicitly staged the risk figure as a problem, she carefully practised the ideals of neutral information, and patient autonomy and decision-making. Throughout the conversation she seemed cautiously aware of not being directive: she avoided presenting the risk as either high or low; she refused to compare Peter and Patricia's risk figure with the risk figures of other patients; she transferred authority from herself to the couple ('it is difficult for me to answer because I am not you, so ...'); she made space for their use of the lottery as a framework for interpreting the figure as either high or low. Yet in her efforts to systematically practise the ideal of the free choice, she only provided the couple with blank answers and no firm platform on which to make sense of and evaluate the risk figure. We will argue that the lack of this firm platform is closely related to the simultaneous implicit meta-communication of the risk figure as problematic (the spatial aspects of the conversation; the emphasis put on the difference between age-related risk and actual risk) and the explicit refusal of being explicit about the indirect problematisation.

In discussing this case, our aim is not to evaluate the efforts of a specific nurse, but to point to the organisational practices and problem spaces that emerge when ideals of autonomy are inscribed into the practices of PRA. What seems to happen in this situation is that the guidelines' problematisation of specific pregnancies (the ones with a risk figure of $c .1: 300$ ) and their emphasis on respecting the pregnant mother's anxieties and requests contribute to a simultaneous problematisation of pregnancies with risk figures that are lower than the cut-off point and a reluctance to provide any form of guidance on what the couple might do with their problem. Said differently, responsibility is redistributed so that antenatal care 'takes on' the responsibility of staging the problem, yet responsibility for defining the solution to the problem is redirected to the couple without providing them with any guidance.

\section{Reflecting upon PRA and making complex risk figures meaningful}

When talking to Patricia after the conversation with the nurse, she said, 'I am happy that I have seen a foetus which looks normal, but I am not thrilled 
about being assessed as having a risk which is higher than my age risk alone'. Peter continued:

If she could just tell me 'Well, the last twenty couples I have seen had a risk between $1: 2$ and 1:2000' and there was this amount of couples in every category, then I think I could use this figure. Yet, I do not think that I can use a figure of 1:661 for anything. I know that she says that it is in relation to the population as such, and so on. But actually I cannot use that figure, because I have nothing to compare with.

While risk figures from the ideal perspective of the guidelines are taken to be value-neutral and, as such, provide an informed platform for autonomous decision-making, Peter and Patricia's case renders visible the experience of the exact opposite. They were confused about the meaning of the risk figure and did not see themselves as informed agents able to make a rational decision. Rather, they expressed that they expected to achieve more clear knowledge about whether the foetus was diseased or not, being at the same time well aware that they could have been more prepared from the outset. In this sense, their experience of the PRA illustrates how 'attempts to control, reduce or remove uncertainty may actually lead to the generation of further uncertainty or the accentuation of existing uncertainty' (Jenkins et al. 2005: 17). In the situation of facing uncertainty they expressed disappointment with their conversation with the nurse. Patricia said:

\footnotetext{
She could have said that a risk at 1:661 is a very small risk. If she had sounded more confident and not like she was not willing to say anything at all and that it was totally up to us then we might have been calmer from the start ... I actually thought that it was a fine result and a small risk, when she explained it to us, but the way she asked 'what do you think about that?' was as if she did not think it was good enough, and then I got worried.
}

What is spelled out here is the way in which the positive words of 'respect of the patient's perspective' and 'non-directiveness' that pervade the guidelines and shape the practice of PRA give rise to patients' experiences of being left to themselves, in limbo and with a very limited space for action.

Seeking to make sense of the risk figure, Peter and Patricia's thoughts circled around whether it was to be considered a high or a low risk. As such, they continued the negotiation they initiated in their conversation with the nurse, a negotiation about how to move from risk figures concerning populations to their own specific foetus, in other words, whether or not the epidemiological risk figure of 1:661 is an indication of a healthy child or a diseased child. While from a statistical perspective risk is a relative figure, a number on a scale (1:661, 1:1000, 1:12 000), risk experienced in lived life is always an either/or question (diseased or healthy). Seeking to find answers to the question, Patricia compared her risk figure with the risk figure of fri- 
ends who had been assessed as having a figure 'way beyond 1:1000', a comparison that made Patricia consider her own risk as rather high.

The cut-off point is another powerful ordering tool used by the pregnant women and their partners when seeking to make sense of the risk figures. Patricia said: 'I think it is nice that at least you have a figure you can relate to. I know that it is also rather arbitrary, but then there is at least something you can relate to. In her case the cut-off point came to serve as what another pregnant woman have described as 'an anchor in chaos'. By making the cutoff point a reference point, Patricia managed to think of her own risk figure of 1:661 as low. In general, pregnant women and their partners express the view that there is a good medical reason for the cut-off point to be established at 1:300, although at the same time they are very aware that they do not know what these reasons are. The cut-off point thereby becomes a tool to reduce the complexity of risk knowledge and point to a specific action: either further examinations or no further examinations. What comes to the fore here is a strong trust in medical experts and guidelines, and a resistance against accepting them as simply neutral providers of information.

While the guidelines emphasise principles of non-directiveness, autonomy and neutral information, they also establish a cut-off point that in a very implicit way indicates preventive values by pointing to the need to act in the present to avoid the future of a child with Down's syndrome. What stands out from our analysis of Patricia and Peter's case is the constitution of a problem space in which the cut-off point to a much larger extent than all the powerful words about autonomy becomes a platform for sense- and decision-making. So, while the guidelines seek to reconfigure the relationship between health professionals and patients in the direction of stronger patient involvement and patient authority in decision-making processes, the patients seek to reinstall authority in the health care setting. In a quite intriguing way the cut-off point comes to take centre stage in this negotiation of who has authority. If we are correct in our interpretation of the conversation between the nurse and Peter and Patricia, the nurse would have been willing to negotiate the cut-off point and allow Peter and Patricia to gain access to further examinations. Yet, the actions of Peter and Patricia (asking the nurse about what they should do, trusting the cut-off point, etc.) indicate a strong wish not to make medical authority negotiable. Further, when left in limbo, their general trust in the public health care system led them to accept the cut-off point. That is, to gain existential footing they transferred authority to the cut-off point and thereby constituted their decision to undergo no further examinations as the right one. 


\section{Accountability in the context of prenatal risk assessment: a matter of informed choice?}

In his compelling analysis of contemporary society, Nikolas Rose (2001) argues that the politics of life itself has taken on a new form. He refers to this new form of politics as etho-politics and describes how in the era of ethopolitics we 'are faced with the inescapable task of deliberating about the human worth of different human lives ... with controversies over such decisions, with conflicts over who should make such decisions and who cannot, and hence with a novel kind of politics of life itself' (Rose 2001: 22). Ethopolitics is a politics derived from the 'self-techniques by which human beings should judge themselves to make themselves better than they are' (Rose 2001: 18). In this space, he argues, risk has become the organising principle that pervades a life in which choice takes central stage. When making choices, biological identity becomes bound up with more general norms of an enterprising, self-actualising, and responsible personhood (Rose 2001: 18).

In a number of ways, our analysis of the practice of PRA in Denmark demonstrates the form of etho-politics described by Rose. What comes to the fore in our material is the way in which negotiations (and controversies) over 'life itself' take place and are shaped in relationships between 1) the policy of autonomous decision-making with its emphasis on both self-deliberation and preventive values, 2) the institutional space of antenatal care in which health professionals administer the new choices, knowledge and technologies made available to all pregnant women by the policy, and 3) the pregnant women and their partners who are to make sense of risk figures and may end up in unexpected negotiations over life. In this new space of action etho-political questions about future life present themselves as choices to be made by the pregnant woman and her partner.

However, while our analysis of the practice of PRA supports a picture of contemporary life as a life of choice, it also contests this picture. Whereas Rose argues that risk has become the organising principle of a 'life of prudence, responsibility and choice' (Rose 2001: 18), our study demonstrates that the question of PRA is so embedded in an organisational routine that although it may be staged as choice it is hardly experienced as such by the people involved. Furthermore, when the urgency to choose suddenly reappears in the context of an ambiguous risk figure, choices do not emerge as prudent acts to be performed by the individual couple, but as complicated temporal processes of meaning-making taking place in the relational space between the clinical setting, professional authority and the social life of the couples who undergo PRA. Indeed, in the face of complex risk information our study renders visible that PRA users are reluctant to 'take on the choice' and to give up the health professionals as authoritative experts. Thus, while 
the guidelines intend to transfer authority to the pregnant woman and her partner, the users of PRA seek to reinstall authority in the medical experts and demonstrate a sturdy trust in the medical experts and their policies, such as the cut-off point. Thereby, in a very intriguing way trust becomes the means through which preventive aims intended by the cut-off point are achieved. The irony here is that the new guidelines on prenatal testing in Denmark were written in opposition to the old prenatal screening programme, which was perceived as being pervaded by a paternalistic and even eugenic ideology representing an unacceptable intrusion by the state into the lives of individuals. As our analysis has shown, the new programme seems to direct people's decisions towards the same preventive effects - only using choice as its moving power.

In a European context the debate about the provision of risk information in the context of health care has been framed mainly as a political and human rights issue. Proponents have emphasised the potential of risk information to empower the individual. In such regimes of health care, the patient is no longer viewed as someone to be cared for by paternalistic medicine, but as a customer having the right to know and to choose health care services (Lupton 1997; Petersen \& Bunton 2002). However, this supposed move towards greater patient empowerment may result in other kinds of action regulation, whereby individuals are implicitly engaged to participate in preventive medicine through choice (Lupton 1997; Novas \& Rose 2000). Such forms of action regulation do not work through coercive means but through the creation of new spaces of action which allow people to regulate themselves and their relationship with others. When assumptions about autonomy and self-determination are inscribed into the social practice of PRA a new configuration of responsibility evolves between the couple and their relationship to their foetus. Couples undergoing PRA come to understand themselves as responsible for the choice being made and thus for the future of foetal life. Paradoxically, this calls into question the assumption underlying the new guidelines that more choice and more information is a source of empowerment and control. While several scholars have debated the question of whether informed choices are reached in practice (Dahl et al. 2006b; Hunt et al. 2006; Marteau et al. 2001; Ormond et al. 2007), what constitutes appropriate information (Dahl et al. 2006a; Pilnick 2004; Van den Berg et al. 2006) and whether this is always in the best interest of health consumers (Chadwick 1997; Williams et al. 2002) the premise that information is empowering is, in the main, taken as a given. This study, however, contests this assumption.

The outcome of the programme of prenatal examinations in Denmark is undoubtedly in accordance with the preventive intentions which are implicit in the cut-off point. The new risk assessment selects more precisely highrisk pregnancies for further diagnostic examinations than the previously 
used age criterion; the detection rate has increased, the number of invasive tests has been reduced and fewer healthy foetuses are aborted. Thus, from a preventive point of view the new programme for prenatal examination in Denmark is a success. As far as the aims of self-determination and autonomy go, our study points to the ways in which knowledge about risks is conditioned by implicit social understandings (of what is problematic, nor$\mathrm{mal}$ and desirable) and appears as lacking in meaning when the existence of such understandings are ignored in the pursuit of neutral facts. Interestingly, the pursuit of neutral facts seems to be in disagreement with what is actually requested - and desired - by users in the process of decisionmaking. A shared value about PRA as the right pathway towards having a healthy baby has come to the fore in the process of decision-making. If the Danish Board of Health were to recognise that the value of prevention underlying the whole organisation of prenatal testing in Denmark is shared by the users, then a shared responsibility of its use and the outcome of the programme might emerge. This would represent an ethics of a shared responsibility which is more in agreement with how decisions are actually made.

\section{Notes}

1 In some cases also pregnant women who show an increased level of anxiety are offered PRA. This possibility has been widely debated in Norway (B. Solberg, Associate Professor of Bioethics, NTNU, Norway, personal communication 2008).

2 The study was conducted in the counties of Århus and Viborg. The total uptake of PRA was $77 \%$, of which $21 \%$ did not participate in a full PRA due to twin pregnancies, technical difficulties, a gestation age above $13+6$, and failing procedures (Tørring et al. 2008).

3 The number of diagnosed foetuses with Down's syndrome in the two counties, which had a total population of c.5500 in the period 1996-2004, was 10-12 per year. By 2005 this number had increased to 18 per year (Tørring et al. 2008).

4 Statistically, around 5\% will receive a risk above the cut off point and around $80 \%$ will receive a risk below 1:1000 (Tabor 2006).

5 A note on methodology: NS met Patricia and Peter at an ultrasound clinic where she observed their ultrasound scan and the communication of risk information after the scan. She also undertook interviews with them after the risk assessment had been carried out, and visited them at their home eight weeks after the scan. The communication session and the interviews were tape-recorded and transcribed. The first interview took place at the hospital after the risk information session and lasted 1.5 hours. It was loosely structured around the following issues: previous knowledge about PRA, motivations, considerations and thoughts about undergoing PRA, preceding expectations, the experience at the ultrasound clinic (including the scan and the information session), perception of the risk number and considerations and expectations regarding the future. The second interview took place eight weeks after the scan and was conducted in the couple's home. This interview lasted 2 hours and 
focused on how they experienced the whole process of undergoing PRA in retrospect and considerations of how and in which ways PRA had interfered with their experience of pregnancy.

\section{Literature}

Bioteknologinemnda. (2005) Søknad om å tilby blodprøverundersøkelser («dobbeltest» og trippeltest») til gravide kvinner som opfyller et eller flere av dagens vilkår for fosterdiagnostik. Oslo: Bioteknologinemnda.

Chadwick, R. (1997) The philosophy of the right to know and the right not to know. In The Right to Know and the Right Not to Know, eds. R. Chadwick, M. Levitt \& D. Shickle, p.13-22. Aldershot: Ashgate Publishing Limited.

Corrigan, O. (2003) Empty ethics: The problem with informed consent. Sociology of Health and Illness, 25, p.768-792.

Dahl, K., Kesmodel, U., Hvidman, L. \& Olesen, F. (2006a) Informed consent: Attitudes, knowledge and information concerning prenatal examinations. In Acta Obstetricia et Gynecologica Scandinavia, 85 (12), p.1414-1419

Dahl, K., Kesmodel, U., Hvidman, L. \& Olesen, F. (2006b) Informed consent: Providing Information about Prenatal Examinations. In Acta Obstetricia et Gynecologica Scandinavia, 85 (12), p.1420-1425.

Folketingsvedtagelse af 15. maj 2003 vedrørende fosterdiagnostik, V105 [Parliamentary Decision on Prenatal Diagnosis, May 15, 2003].

Franklin, S. \& Roberts, C. (2006) Born and made. An Ethnography of Preimplantation Genetic Diagnosis. New Jersey: Princeton University Press.

Gifford, S.M. (1986) The Meaning of Lumps: A Case Study of the Ambiguities of Risk. In Anthropology and Epidemiology, eds. M. Lock, A. Young \& A.D. Gaines, p.231-249. Dordrecht: D. Reidel Publishing Company.

Haimes, E. (2002) What can the social sciences contribute to the study of ethics? Theoretical, empirical and substantive considerations. Bioethics, 16 (2), p.89113.

Harper, P.S. (2004) Practical Genetic Counselling. London: Arnold.

Hedgecoe, A.M. (2004) Critical bioethics: Beyond the social science critique of applied ethics. Bioethics, 18 (2), p.120-143.

Helén, I. (2005) Risk management and ethics in antenatal care. In Genetic Governance. Health, Risk and Ethics in the Biotech Era, eds. R. Bunton \& A. Petersen, p.47-63. London: Routledge.

Hoeyer, K. (2005) Studying ethics as policy: The naming and framing of moral problems in genetic research. Current Anthropology, 46, p.71-90.

Hoffmaster, B. (ed.) (2001) Bioethics in Social Context. Philadelphia: Temple University Press.

Holm, S. \& Monique, F.J. (eds.) (2004) Engaging the World: The Use of Empirical Research in Bioethics and the Regulation of Biotechnology. Amsterdam: IOS Press.

Howell, S. (ed.) (1997) The Ethnography of Moralities. London: Routledge.

Hunt, L.M., Castaneda, H. \& de Voogd, KB. (2006) Do notions of risk inform patient choice? Lessons from a study of prenatal genetic counselling. Medical Anthropology, 25 (3), p.193-219. 
Indenrigsministeriet [Ministry of the Interior] (1977) Betonkning om pronatal genetisk diagnostic [Report about Prenatal Genetic Diagnosis], nr. 803. Copenhagen: The Danish Publish House.

Jenkins, R., Jessen, H. \& Steffen, V. (2005) Matters of life and death. The control of uncertainty and the uncertainty of control. In Managing Uncertainty. Ethnographic Studies of Illness, Risk and the Struggle for Control, eds. R. Jenkins, H. Jessen and V. Steffen, p.9-29. Copenhagen: Museum Tusculanum Press.

Jöhncke, S., Svendsen, M.N. \& Whyte, S.R. (2004) Løsningsmodeller. Sociale teknologier som antropologisk arbejdsfelt. In Viden om verden. En grundbog $i$ antropologisk analyse, ed. K. Hastrup, p.385-407. Copenhagen: Hans Reitzel Forlag.

Kerr, A. (2004) Reproduction. In Genetics and Society, A. Kerr,. p.64-83. London: Routledge.

Koch, L. (2003) Fosterundersøgelser og selvbestemmelse. Månedsskrift for praktisk loegegerning, p.989-1002.

Konrad, K. (2005) Narrating the New Predictive Genetics. Ethics, Ethnography and Science. Cambridge: Cambridge University Press.

Kristjánsdóttir, H. (2008) Formand for Nordisk Jordemor Forening (NFJ) [President for the Nordic Midwife Association]. Personal communication.

Lemke, T. (2005) From eugenics to the government of genetic risks. In Genetic Governance. Health, Risk and Ethics in the Biotech Era, eds. R. Bunton \& A. Petersen, p.95-106. London: Routledge.

Lock, M. (1998) Perfecting society: Reproductive technologies, genetic testing, and the planned family in Japan. In Pragmatic Women and Body Politics, eds. M. Lock \& P.A. Kaufert, p.206-239. Cambridge: Cambridge University Press.

Lou, S., Dahl, K., Risør, M.B., Hvidman, L., Thomsen, S.G. \& Jørgensen, F.S. (2007) En kvalitativ undersøgelse af gravides valg af nakkefoldsskanning. Ugeskrift for loeger, 169, p.914-918.

Lupton D. (1997) Foucault and the medicalisation critique. In Foucault, Health and Medicine, eds. A. Petersen \& R. Bunton, p.94-110, London: Routledge.

Lupton, D. (1999) Risk and the ontology of pregnant embodiment. In Risk and Sociocultural Theory: New Directions and Perspectives, ed. D. Lupton, p.59-85. New York: Cambridge University Press.

Marteau, T.M. \& Dormandy, E. (2001) Facilitating informed choice in prenatal testing: How well are we doing? American Journal of Medical Genetics, 106 (3), p.185-190.

Marteau, T.M., Dormandy, E. \& Michie, S. (2001) A measure of informed choice. Health Expectations, 4, p.99-108.

Nicolaides, K.H. (2004) The 11-13 week scan. London: Fetal Medicine Foundation.

Novas, C. \& Rose, N. (2000) Genetic risk and the birth of the somatic individual. Economy \& Society, 29, p.485-513.

Ormond, K.E., Iris, M., Banuvar, S., Miogue, J., Annas, G.J. \& Elias, S. (2007) What do patients prefer: Informed consent models for genetic carrier testing. Journal of Genetic Counselling, 16 (4), p.539-550.

Petersen, A. \& Bunton, R. (2002) The New Genetic and Public's Health. London: Routledge.

Pilnick, A. (2004) «It's just one of the best tests that we've got at the moment»: The presentation of nuchal translucency screening for fetal abnormality in pregnancy. Discourse \& Society, 15 (4), p.451-465. 
Rapp, R. (2000) Testing Women, Testing the Fetus. The Social Impact of Amniocentesis in America. New York: Routledge.

Rose, N. (2001) The politics of life itself. Theory, Culture and Society, 18 (6), p.1-30.

Rose, N. (2007) The Politics of Life Itself, Biomedicine, Power, and Subjectivity in the Twenty-First Century. New Jersey: Princeton University Press.

Schwennesen, N. (2005) Forplantning, valg og viden. Om præ-implantationsdiagnostikkens (PGD) moralske og sociale implikationer. GRUS, 26 (75-76), p.8497.

Shore, C. \& Wright, S. (1997) Policy: A new field of anthropology. In Anthropology of Policy: Critical Perspectives on Governance and Power, eds. C. Shore \& S. Wright, p.3-39. London: Routledge.

Socialdepartementet (2006) Genetisk integritet $\mathrm{mm}$. Stockholm: Socialdepartementet, Prop.2005/06:64.

Solberg, B. (2008) Associate Professor in bioethics, NTNU, Norway. Personal communication.

Sundhedsstyrelsen [Danish Board of Health] (2003a) Fosterdiagnostik og risikovurdering [Prenatal Diagnosis and Risk Assessment]. Copenhagen: Schultz Information.

Sundhedsstyrelsen [Danish Board of Health] (2003b) Notat vedrørende nye retningslinjer for fosterdiagnostik. [Note Regarding New Guidelines of Prenatal Diagnosis]. Copenhagen: Danish Board of Health.

Sundhedsstyrelsen [Danish Board of Health] (2004) Nye retningslinjer for fosterdiagnostik [New Guidelines for Prenatal Diagnosis]. Copenhagen: Danish Board of Health.

Svendsen, M.N., \& Koch, L. (2006) Genetics and prevention: A policy in the making. New Genetics and Society, 25 (1), p.51-68.

Tabor, A. (2006) Professor in foetal medicine, Rigshospitalet. Personal communication. Copenhagen: Denmark.

Tørring, N., Petersen, B.B.O., Holmskov, A., Hertz, M.J. \& Uldbjerg, N. (2008) Prænatal diagnostik i Århus og Viborg Amter efter implementering af første trimester-risikovurdering. Ugeskrift for loeger, 170, p.50-54.

Van den Berg, M., Timmermans, D.R.M., ten Kate, L.P., van Vugt, J.M.G. \& van der Wal, G. (2006) Informed decision making in the context of prenatal screening. Patient Education and Counseling, 63 (1-2), p.110-117.

Webster, A. (2007) Crossing boundaries. Social science in the policy room. Science, Technology \& Human Values, 32 (4), p.458-478.

Weir, L. (1996) Recent developments in the government of pregnancy. Economy and Society, 25 (3), p.373-392.

Williams, C., Sandall, J., Lewando-Hundt, G., Heyman, B., Spencer, K. \& Grellier, R. (2002) Women as moral pioneers? Experiences of first trimester antenatal screening. Social Science \& Medicine, 61 (9), p.1983-1992. 